\title{
Activation of Trace Amine-Associated Receptor 1 Stimulates an Antiapoptotic Signal Cascade via Extracellular Signal-Regulated Kinase $1 / 2$
}

\author{
Xiao Shi, Tracy L. Swanson, Nicholas B. Miner, Amy J. Eshleman, and Aaron Janowsky \\ Research Service, Veterans Affairs Portland Health Care System, Portland, Oregon (X.S., T.L.S., N.B.M., A.J.E., A.J.); and The \\ Methamphetamine Abuse Research Center (X.S., A.J.) and Departments of Psychiatry (X.S., T.L.S., A.J.E., A.J.) and Behavioral \\ Neuroscience (N.B.M., A.J.E., A.J.), Oregon Health and Science University, Portland, Oregon
}

Received March 29, 2019; accepted August 2, 2019

\begin{abstract}
Methamphetamine (MA) is highly addictive and neurotoxic, causing cell death in humans and in rodent models. MA, along with many of its analogs, is an agonist at the $G$ protein-coupled trace amine-associated receptor 1 (TAAR1). TAAR1 activation protects against MA-induced degeneration of dopaminergic neurons, suggesting that TAAR1 plays a role in regulating MA-induced neurotoxicity. However, the mechanisms involved in TAAR1's role in neurotoxicity and cell death have not been described in detail. In this study, we investigated the apoptosis pathway in Taar1 wild-type (WT) and knockout (KO) mice and in cells expressing the recombinant receptor. $\mathrm{Bcl}-2$, an antiapoptotic protein, was upregulated $\sim 3$-fold in the midbrain area (substantial nigra and ventral tegmental area) in Taar1 $\mathrm{KO}$ compared with WT mice, and MA significantly increased $\mathrm{Bcl}-2$ expression in WT mice but decreased $\mathrm{Bcl}-2$ expression in $\mathrm{KO}$ mice. The proapoptotic protein Bax did not differ across genotype or in response to $\mathrm{MA}$. Bcl-2 expression was significantly upregulated by the TAAR1 agonist RO5166017 ((S)-4-[(ethyl-phenyl-amino)methyl]-4,5-dihydro-oxazol-2-ylamine) in cells expressing the recombinant mouse TAAR1. Additionally, activation of TAAR1
\end{abstract}

by R05166017 increased phosphorylation of extracellular signalregulated kinase (ERK) 1/2, and protein kinase $B(A K T)$, but only inhibition of ERK1/2 phosphorylation prevented TAAR1induced increases in $\mathrm{Bcl}-2$ levels, indicating that TAAR1 activation increases $\mathrm{Bcl}-2$ through an ERK1/2-dependent pathway. All changes to ERK $1 / 2$ pathway intermediates were blocked by the TAAR1 antagonist, $\mathrm{N}$-(3-ethoxyphenyl)-4-(1pyrrolidinyl)-3-(trifluoromethyl) benzamide. These findings suggest that TAAR1 activation protects against MA-induced cell apoptosis and TAAR1 may play a role in cell death in neurodegenerative diseases.

\section{SIGNIFICANCE STATEMENT}

Methamphetamine stimulates TAAR1, a G protein-coupled receptor. The role and mechanisms for TAAR1 in methamphetamineinduced neurotoxicity are not known. Here, we report that, in genetic mouse models and cells expressing the recombinant receptor, TAAR1 activates the ERK1/2 pathway but not the AKT pathway to upregulate the antiapoptotic protein Bcl-2, which protects cells from drug-induced toxicity.

\section{Introduction}

Methamphetamine (MA) increases dopamine (DA) and serotonin release via interaction with plasma membrane transporters and vesicular monoamine transporter 2. Chronic or high-dose acute MA administration causes persistent damage

This research was funded by The Department of Veterans Affairs Merit Review [Grant I01BX002758] and Career Scientist Programs, the Department of Justice Drug Enforcement Administration [Interagency Agreement D-15-OD0002], the Methamphetamine Abuse Research Center [Grant P50 DA018165], and the National Institutes of Health National Institute on Drug Abuse [Interagency Agreement ADA12013].

The contents of this work do not represent the views of the US Department of Veterans Affairs or the United States Government.

The authors have no conflicts of interest with the content of this article. https://doi.org/10.1124/mol.119.116798. to monoaminergic terminals (O'Callaghan and Miller, 1994; Kadota and Kadota, 2004; Tulloch et al., 2011; Miner et al., 2017). Many studies have described the neurochemical etiology for MA-induced neurotoxicity, including oxidative stress, gliosis, and involvement of the ubiquitin-proteasome system (Cadet and Brannock, 1998; Thomas et al., 2004; Smith et al., 2012); however, the cellular mechanisms involved in MA-induced toxicity have not been described in detail.

MA is an agonist at $\mathrm{G}$ protein-coupled trace amine-associated receptor 1 (TAAR1) inside the cell (Bunzow et al., 2001). TAAR1 is stimulated by trace amines, including tyramine, $\beta$-phenethylamine, octopamine, tryptamine, and thyronamine derivatives (Bunzow et al., 2001; Hart et al., 2006). TAAR1 is also activated by a variety of MA analogs, including amphetamines,

ABBREVIATIONS: AKT, protein kinase B; AMPH, amphetamine; Cl-Casp3, cleaved caspase 3; DA, dopamine; EPPTB, $N$-(3-ethoxyphenyl)-4-(1pyrrolidinyl)-3-(trifluoromethyl) benzamide; ERK, extracellular signal-regulated kinase; GSK2334470, (3S,6R)-1-[6-(3-Amino-1H-indazol-6-yl)-2(methylamino)-4-pyrimidinyl]-N-cyclohexyl-6-methyl-3-piperidinecarboxamide; HEK, human embryonic kidney; KO, knockout; MA, methamphetamine; mTAAR1, mouse trace amine-associated receptor 1; pERK, phosphorylated extracellular signal-regulated kinase; pro-Casp3, procaspase 3; RO5166017, (S)-4-[(ethyl-phenyl-amino)-methyl]-4,5-dihydro-oxazol-2-ylamine; RO5263397, (S)-4-(3-Fluoro-2-methyl-phenyl)-4,5-dihydro-oxazol-2ylamine; Ser573, serine 473; TAAR1, trace amine-associated receptor 1; Thr308, threonine 308; U0126, (1,4-Diamino-2,3-dicyano-1,4-bis(2aminophenylthio)butadiene); WT, wild type. 
structurally related abused drugs, and ergolines (Bunzow et al., 2001), suggesting this receptor is a novel target that plays a role in drug addiction. A number of signal cascades are linked to receptor activation. For instance, stimulation of $\mathrm{G}_{\mathrm{s}}$-coupled TAAR1 increases intracellular adenylyl cyclase-mediated cAMP and triggers inwardly rectifying $\mathrm{K}^{+}$channels (Borowsky et al., 2001; Bunzow et al., 2001; Miller et al., 2005; Bradaia et al., 2009). In lymphocytes, activation of TAAR1 leads to protein kinase A and protein kinase $\mathrm{C}$ phosphorylation, increasing transcription factors, cAMP response element binding protein, and nuclear factor of activated T-cells (Panas et al., 2012). The TAAR1 agonist, RO5263397 ((S)-4-(3-Fluoro-2-methyl-phenyl)-4,5-dihydro-oxazol2-ylamine), induces phosphorylation of extracellular signalregulated kinase (ERK) 1/2 and cAMP response element binding protein in transfected human embryonic kidney (HEK) 293 cells (Espinoza et al., 2018). TAAR1 signaling also involves the $\mathrm{G}$ protein-independent, $\beta$-arrestin2-dependent pathway via protein kinase $\mathrm{B}(\mathrm{AKT}) /$ glycogen synthase kinase-3 $\beta$ (Harmeier et al., 2015; Asif-Malik et al., 2017). To date, most studies of TAAR1 have focused on its role in modulating monoaminergic transmission, and other intermediates of TAAR1 signaling have not been extensively studied.

MA causes neuronal apoptosis mediated by stress to mitochondria and endoplasmic reticulum (Deng et al., 2001, 2002; Choi et al., 2002; Jayanthi et al., 2004). Apoptosis maintains homeostasis in response to different stimuli and has been implicated in neurodegenerative disorders including Parkinson's disease, Huntington's disease, and Alzheimer's disease (Mattson, 2000). The endogenous TAAR1 agonists $\beta$-phenethylamine and tyramine increase apoptosis in TAAR1expressing malignant B cells (Wasik et al., 2012). In addition, activation of TAAR 1 is involved in neuronal degeneration of a 6-hydroxydopamine-induced Parkinson's disease model (Alvarsson et al., 2015). 3-Iodothyronamine, a TAAR1 agonist, has a neuroprotective role against spinal cord injury through an antiapoptotic mechanism ( $\mathrm{Lv}$ et al., 2018). These reports suggest that TAAR 1 may play a role in modulating cell death, but the signal cascades have not been elucidated.

Administration of MA to mice changes the anti- and proapoptotic proteins, Bcl-2 and Bax, and induces neuronal apoptosis (Stumm et al., 1999; Jayanthi et al., 2001, 2004). Bcl-2 promotes cell survival during apoptosis, while other members of the Bcl-2 family, such as Bax, accelerate apoptosis. Bcl-2 dimerizes with Bax, preventing Bax activation and damage to the mitochondrial membrane; therefore, the proapoptotic:antiapoptotic (Bax:Bcl-2) ratio is an indicator of apoptosis, demonstrating either activation or inhibition of mitochondrial-dependent cell death (Korsmeyer et al., 1993). Overexpression of Bcl-2 protects against MA-induced apoptosis in neuronal cells (Cadet et al., 1997), and MA-induced neural apoptosis is mediated by the caspase cascades, which include caspase 3,9 , and 11 , the downstream executioners that lead to DNA fragmentation and cell death (Deng et al., 2002; Huang et al., 2015). The role of TAAR1 in the MA-induced expression of these intermediates is not known.

We hypothesized that TAAR1 protects against MA-induced neurotoxicity via activation of a specific signaling pathway. Our data indicate that the antiapoptotic protein Bcl-2 and ERK1/2 phosphorylation are upregulated in midbrain of Taar1 wild-type (WT) mice following MA administration, but not in Taar1 knockout (KO) mice. Furthermore, Bcl-2 levels were upregulated by the TAAR 1 agonist in cells expressing the recombinant mouse TAAR1 (mTAAR1); however, Bax levels were unchanged. Activation of TAAR1 increased ERK1/2 and AKT phosphorylation, and blocking TAAR1 activation or TAAR1induced ERK phosphorylation (but not AKT phosphorylation) prevented TAAR1 agonist-induced upregulation of Bcl-2 expression. Our results indicate for the first time that TAAR1-mediated ERK phosphorylation plays a protective role in cell death, and may have implications for the etiology and treatment of neurodegenerative diseases.

\section{Materials and Methods}

Drugs and Reagents. Racemic methamphetamine hydrochloride was generously provided by the Drug Supply Program of the National Institute on Drug Abuse (Bethesda, MD). The TAAR1 agonist RO5166017 ((S)-4-[(ethyl-phenyl-amino)-methyl]-4,5-dihydro-oxazol-2-ylamine) was synthesized according to a published procedure (US 2012/0028964 A1) by the Oregon Health and Science University Medicinal Chemistry Core. $N$-(3-ethoxyphenyl)-4-(1-pyrrolidinyl)-3-(trifluoromethyl) benzamide (EPPTB) was generously provided by Dr. Peter Meltzer (Organix Inc., Woburn, MA). U0126, (1,4-Diamino-2,3-dicyano-1,4bis(2-aminophenylthio)butadiene) a mitogen-activated protein kinase/ ERK1/2 inhibitor, was obtained from Cell Signaling Technology (Danvers, MA). RO5166017 and U0126 were first dissolved in DMSO at concentrations of 100 and $10 \mathrm{mM}$, respectively. RO5166017 was subsequently diluted in $1 \%$ acetic acid to $1 \mathrm{mM}$, and then further diluted into culture medium at the concentrations designated. GSK2334470 ((3S,6R)-1-[6-(3-Amino-1H-indazol-6-yl)-2-(methylamino)-4-pyrimidinyl]$N$-cyclohexyl-6-methyl-3-piperidinecarboxamide) was obtained from Tocris Bioscience (Minneapolis, MN). GSK2334470 was dissolved in DMSO at $10 \mathrm{mM}$, and then subsequently diluted into culture medium at $1 \mu \mathrm{M}$ for a final DMSO concentration of $0.1 \%$.

Animals. The breeding and genotyping of the Taar1 KO mice (obtained from the UC Davis Knockout Mouse Project; https:// www.komp.org) were done as previously described (Harkness et al., 2015). Mice (10-20 weeks old) were group housed in filtered acrylic plastic cages $(28 \mathrm{~cm}$ long $\times 18 \mathrm{~cm}$ wide $\times 13 \mathrm{~cm}$ high) lined with ECO-Fresh bedding (Absorption Corporation, Ferndale, WA). Mice of both sexes were used in this study. Mice had free access to rodent chow (5LOD, 5.0\% fat content; Purina Mills, St. Louis, MO) and water ad libitum. Colony room temperature was $21 \pm 1^{\circ} \mathrm{C}$ and lights were maintained on a 12-hour light/dark schedule, with lights on at 6 AM. Procedures were conducted in accordance with the National Institutes of Health Guide for the Care and Use of Laboratory Animals, and were approved by the Veterans Affairs Portland Health Care System Institutional Animal Care and Use Committee.

Drug Treatment and Tissue Dissection. Mice were weighed $($ mean $=26.1$ g, S.E.M. $=0.4 \mathrm{~g}$, six to seven mice/treatment group) and individually housed on the day of MA administration. MA was dissolved in $0.9 \%$ saline and injected in a final volume of $10 \mathrm{ml} / \mathrm{kg}$. After a 1-hour acclimation period, each animal received four intraperitoneal injections (2 hours apart) of saline or MA (5 or $10 \mathrm{mg} / \mathrm{kg}$ ). The ambient temperature of the testing environment was $23 \pm 1^{\circ} \mathrm{C}$. Twenty-four hours after the last saline or MA injection, mice were euthanized by cervical dislocation followed by decapitation. The midbrain area was dissected, snap frozen, and stored at $-70^{\circ} \mathrm{C}$ until use.

Cell Culture. HEK293 or HEK cells stably expressing mTAAR1 (HEK-mTAAR1) were grown in Dulbecco's modified Eagle's medium containing $10 \%$ FetalClone I serum (Thermo Fisher Scientific, Waltham, MA) and maintained in a humidified incubator with $10 \% \mathrm{CO}_{2}$ as previously described (Harkness et al., 2015; Shi et al., 2016). Two days before the treatment, cells were plated in 12-well plates with $1 \times 10^{6}$ cells/well. Cells were treated with RO5166017 $(100 \mathrm{nM})$ at 0 , $2,4,6$, or 18 hours before harvest. For experiments involving the TAAR1 antagonist, cells were incubated with $10 \mu \mathrm{M}$ EPPTB for 45 minutes or 2 hours before addition of agonist. To measure inhibition of ERK1/2 activation, cells were pretreated with $10 \mu \mathrm{M}$ U0126 for 
1 hour before RO5166017 addition. After treatment, cells were washed twice with ice cold PBS and lysed with radioimmunoprecipitation assay buffer before use in western blotting.

cAMP Accumulation Assay. HEK cells were plated at a density of $2 \times 10^{5}$ well in 48 -well tissue culture plates. One day before the assay, cells were switched to culture medium containing $10 \%$ charcoalstripped FetalClone I serum and incubated overnight. Experiments were completed in assay buffer as previously described (Watts et al., 1998). Seven concentrations of RO5166017 $\left(10^{-11}\right.$ to $\left.10^{-5}\right)$ were added and cells were incubated for 60 minutes at $37^{\circ} \mathrm{C}$. cAMP accumulation was measured using a cAMP EIA Kit (Cayman Chemical, Ann Arbor, MI), according to the manufacturer's instructions. All experiments were conducted with duplicate determinations.

Immunoblotting. The midbrain samples and cells were homogenized in radioimmunoprecipitation assay lysis buffer (Millipore, Burlington, MA) containing 1X protease inhibitor (Roche, Branchburg, $\mathrm{NJ}$ ), and then centrifuged at $14,500 \mathrm{~g}$ for 10 minutes at $4^{\circ} \mathrm{C}$. Supernatants were collected for use in the BCA Protein Assay Kit (Thermo Fisher Scientific, Waltham, MA). Equal amounts of protein for each sample were subjected to SDS-PAGE through a 10\%-20\% polyacrylamide gel and transferred to polyvinylidene fluoride membranes (Biorad, Hercules, CA). Membranes were blocked with 5\% nonfat dry milk in Tris-buffered saline/Tween 20 at room temperature for 30 minutes, and then subsequently incubated at $4^{\circ} \mathrm{C}$ overnight with mouse anti-Bcl-2 (1:200; Santa Cruz Biotechnology, Dallas, TX), rabbit anti-Bax (1:1000; Cell Signaling Technology), rabbit anti-phosphorylated ERK (pERK) 1/2 (1:1000; MilliporeSigma), rabbit anti-total ERK1/2 (1:1000; Cell Signaling Technology), rabbit anti-phosphorylated AKT serine
473 (Ser473), rabbit anti-phosphorylated AKT threonine 308 (Thr308), rabbit anti-total AKT (1:1000; Cell Signaling technology), mouse anti$\beta$-actin (1:1000; Santa Cruz Biotechnology), rabbit anti-procaspase 3 (1:2000; Cell Signaling Technology), rabbit anticleaved caspase 3 (1:1000; Cell Signaling Technology), and mouse anticleaved caspase 3 P17 subunit (1:200; Santa Cruz Biotechnology). The immunoblots were incubated with horseradish peroxidase-conjugated secondary antibody. Immune complexes were visualized by chemiluminescence and analyzed using Biorad Quantity One software. Bands were analyzed by densitometry using Image J (National Institutes of Health). The proteins of interest were normalized to $\beta$-actin as an internal control.

Data Analysis. Results from western blotting experiments are presented as mean \pm S.D. Significant differences were assessed by one- or two-way ANOVA for genotype by MA concentration or cell line by treatment time using the program GraphPAD Prism 7 (San Diego, CA). Tukey's multiple comparisons tests were followed by one-way ANOVA and Sidak's multiple comparisons tests were followed by two-way ANOVA. Values of $P<0.05$ were considered significant for all tests.

\section{Results}

MA-Induced Changes in Expression of Bcl-2 and Bax Protein Differ in Taar1 WT and KO Mice. Taar1 WT and $\mathrm{KO}$ mice were injected with 5 or $10 \mathrm{mg} / \mathrm{kg} \mathrm{MA}$ (four times, 2 hours apart). This regimen causes MA-induced neurotoxicity, which includes decreased DA and serotonin content and
A

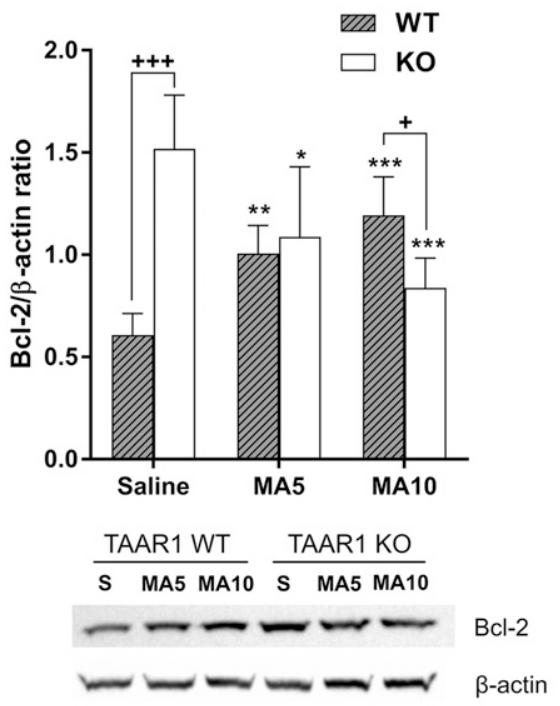

B

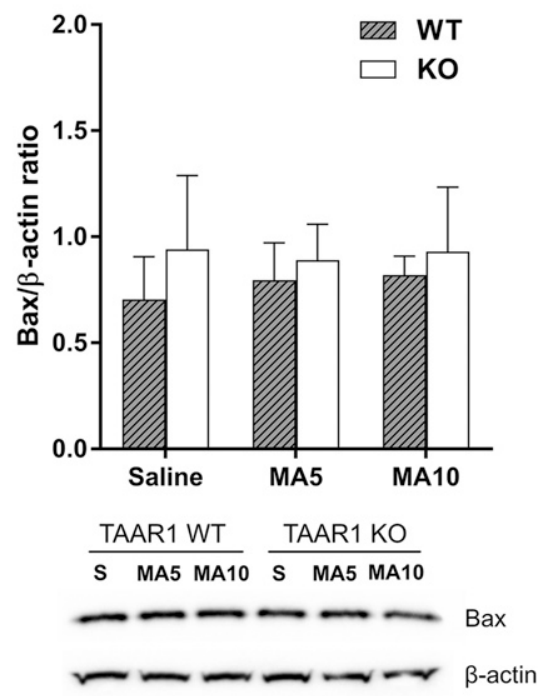

C

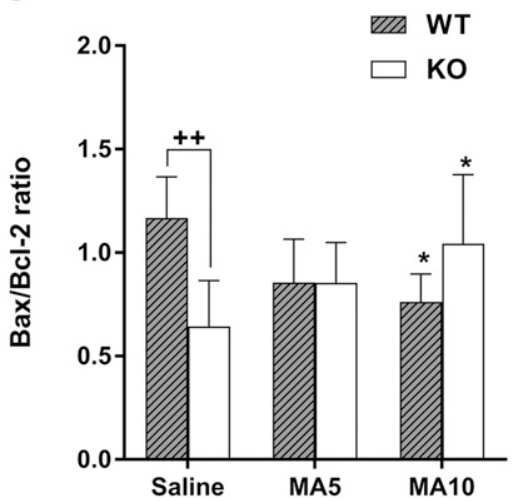

Fig. 1. MA upregulated Bcl-2 protein expression in the midbrain of Taar1 WT mice at 24 hours postinjection, but not in Taar1 KO mice. (A) Basal (salineinjected) Bcl-2 expression was significantly higher in Taar1 KO compared with Taar1 WT mice, and MA dose dependently decreased Bcl-2 expression in Taar1 KO mice and increased Bcl-2 expression in Taar1 WT mice compared with saline-injected animals. The Bcl-2 levels were reduced in Taar1 KO mice at the $4 \times$ $10 \mathrm{mg} / \mathrm{kg}$ dose of MA compared with Taar1 WT mice. Bcl-2 levels were analyzed by two-way ANOVA. There was a significant genotype $\times$ treatment interaction $[F(2,35)=30.74 ; P<0.0001], N=6$ to 7/genotype/ treatment. (B) Bax protein levels were not different between the genotypes and were not affected by MA treatment. (C) The Bax/Bcl-2 ratio was significantly higher in the midbrain of saline-injected Taar1 WT mice compared with Taar1 KO mice. There was a significant genotype $\times$ treatment interaction $[F(2,36)=11.74 ; P<0.001]$ for the $\mathrm{Bax} / \mathrm{Bcl}-2$ ratio Additionally, MA dose dependently increased the Bax/Bcl-2 ratio in Taar 1 KO mice, but decreased the ratio in WT mice. $* P<0.05$; $* * P<0.01$; $* * * P<$ 0.001 vs. saline, $+P<0.05 ;++P<0.01 ;+++P<$ 0.001 between genotypes. Data are mean \pm S.D. 
uptake, reduced tyrosine hydroxylase-positive cells, and diminished astrocyte and microglial expression (Fleckenstein et al., 1997; Thomas et al., 2004; McConnell et al., 2015; Miner et al., 2017). Twenty-four hours after the last injection of saline or MA, immunoblotting was used to examine changes in apoptotic proteins in the midbrain of both genotypes. Bcl-2 expression was significantly higher (almost 3-fold) in salineinjected Taar1 KO mice compared with WT mice. The KO and WT mice are on a homogenous (C57BL/6N) background; therefore, this difference in the basal expression of Bcl-2 is likely the result of genetic manipulation of the Taar1 KO mice. Additionally, MA dose dependently upregulated Bcl-2 expression in Taar1 WT mice (Fig. 1A). However, MA had the opposite effect in $\mathrm{KO}$ mice and dose dependently decreased Bcl-2 expression. This resulted in significantly higher expression of Bcl-2 in the midbrain of Taar1 WT mice compared with Taar1 KO mice at the higher dose of MA. There were no differences in expression of the proapoptotic protein Bax in the midbrain area of WT and KO mice, and Bax expression was not altered by MA (Fig. 1B). Therefore, the Bax/Bcl-2 ratio in the saline-injected mice differed significantly across genotype, and the ratio was higher in the WT mice (Fig. 1C). In Taar 1 WT mice treated with $4 \times 10 \mathrm{mg} / \mathrm{kg} \mathrm{MA}$, the Bax/Bcl-2 ratio was decreased compared with the $\mathrm{Bax} / \mathrm{Bcl}-2$ ratio in (saline) controls because of higher Bcl-2 expression. This evidence suggests that the presence of TAAR1 may affect a signal cascade involved in cell death and implicates endoplasmic reticulum and mitochondrial stress after MA administration.
Activation of Caspase 3 in Taar1 WT and KO Mice after MA Injection. To investigate whether the downstream apoptotic intermediate, caspase 3 , is activated after MA administration, we examined both full-length and cleaved caspase 3 (Cl-Casp3) in midbrain tissue from Taar1 WT and KO mice. Immunoblot analyses of Cl-Casp3 (P17 subunit) indicated that there were no significant differences between the genotypes or effects of MA administration compared with saline-injected control animals (Fig. 2A). Interestingly, the full-length caspase, procaspase 3 (pro-Casp3) was decreased by $4 \times 10 \mathrm{mg} / \mathrm{kg}$ MA treatment in Taar1 KO mice compared with saline-injected animals and WT genotype (Fig. 2, B and D). The ratio of Cl-Casp3/pro-Casp3 was increased in Taar1 $\mathrm{KO}$ mice following $4 \times 10 \mathrm{mg} / \mathrm{kg}$ MA injection compared with saline-injected $\mathrm{KO}$ mice, while no difference in the ratio was observed in Taar1 WT mice across MA doses (Fig. 2C).

In Vitro Activation of TAAR1 Increases Bcl-2 Levels. To directly examine TAAR1-regulated Bcl-2 expression, we first verified the functionality of the receptors by measuring cAMP production in HEK293 cells stably expressing mTAAR1. The selective agonist, RO5166017, dose dependently stimulated cAMP production (Fig. $3 \mathrm{~A}$ ) by mTAAR1. The $\mathrm{EC}_{50}$ value of RO5166017 in HEK-mTAAR1 cells was $1.62 \pm 0.23 \mathrm{nM}$. Subsequently, nontransfected HEK293 cells or stably transfected HEK-mTAAR1 cells were treated with 100 nM RO5166017 or vehicle. Cells were harvested at $0,2,4,6$, and 18 hours after RO5166017 treatment. Expressions of Bcl-2, Bax, and the internal control, $\beta$-actin, were measured by western blotting. The Bcl-2 levels in mTAAR1-expressing cells time dependently
A

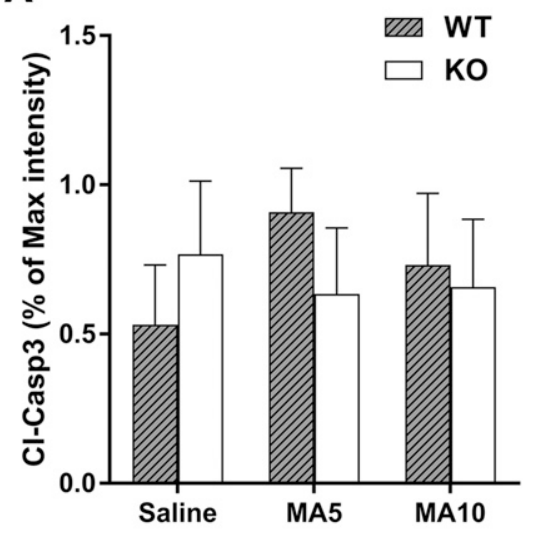

C

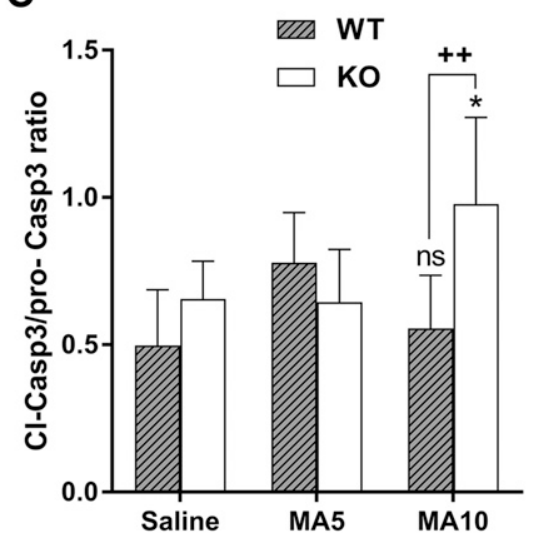

B

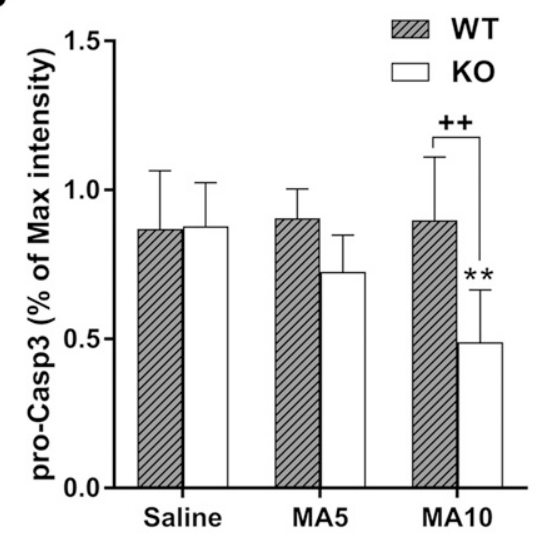

Fig. 2. The expression of cleaved caspase $3(\mathrm{Cl}-$ Casp3) and full-length caspase 3 (pro-Casp3) in the midbrain of Taar1 WT and KO mice at 24 hours after MA administration. (A) The expression of Cl-Casp3 was not different between saline- and MA-injected mice or genotypes. (B) However, proCasp3 in Taar $1 \mathrm{KO}$ mice was decreased after $10 \mathrm{mg} / \mathrm{kg}$ MA treatment. (C) The ratio of Cl-Casp3/pro-Casp3 was significantly higher in Taar1 KO mice after $4 \times 10 \mathrm{mg} / \mathrm{kg}$ MA administration compared with saline-injected controls and MA-injected WT mice. There was a genotype $\times$ treatment interaction $[F(2,35)=6.723 ; P<0.01] . N=6$ to $7 /$ genotype/ treatment. (D) Representative blots showing the expression levels of Cl-Casp3, pro-Casp3, and the internal control, $\beta$-actin. $* P<0.05$; $* * P<0.01$ vs. saline, $++P<0.01$ between genotypes. Data are mean \pm S.D.

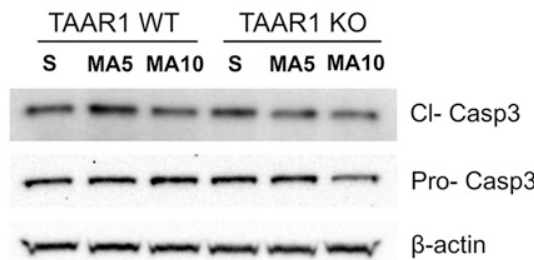


A

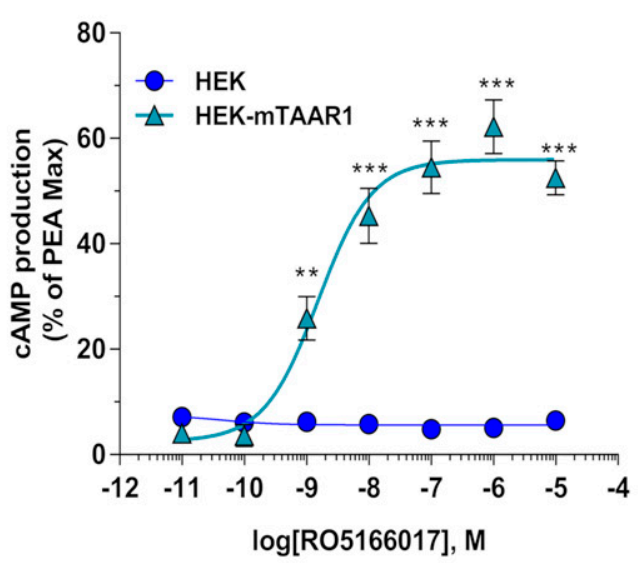

B

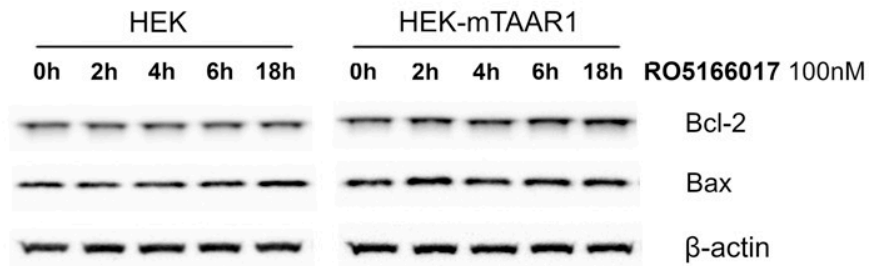

C

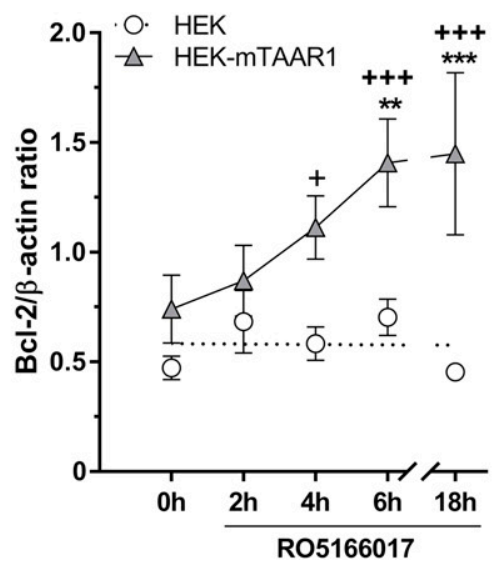

D

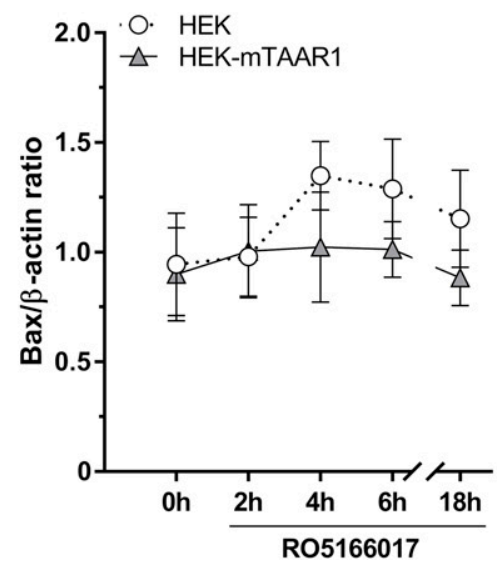

E

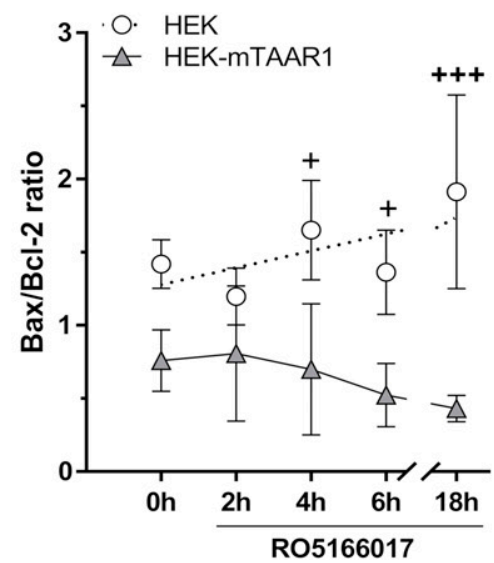

Fig. 3. TAAR1 agonist RO5166017 increased Bcl-2 levels, but not Bax levels in HEK293 cells stably expressing mTAAR1. (A) RO5166017 dose dependently stimulated cAMP production in HEK-mTAAR1 cells. (B) Representative time course of RO5166017 treatment. Nontransfected or HEK-

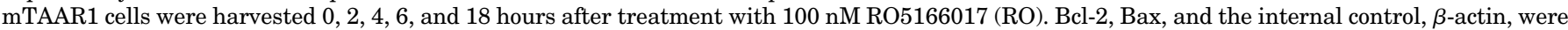
measured by western blot. (C) RO5166017 increased Bcl-2 levels in cells stably expressing mTAAR1 in a time-dependent manner; however, there was no agonist-induced regulation of Bcl-2 in nontransfected HEK293 cells. For Bcl-2, two-way ANOVA indicated an interaction between time $\times$ cell type $[F(4,28)=7.165, P<0.001]$. (D) Bax expression was not changed in nontransfected HEK293 or HEK-mTAAR1 cells. (E) The ratio of Bax/Bcl-2 was significantly lower in HEK-mTAAR1 cells than in nontransfected HEK293 cells. For the Bax/Bcl-2 ratio, there was a significant interaction between time $\times$ cell type $[F(4,28)=5.546, P<0.01]$ by two-way ANOVA. Data shown represent the average of independent experiments, each time point conducted in duplicate. $* * P<0.01 ; * * * P<0.001$ vs. time $(0$ hour $),+P<0.05 ;+++P<0.001$ between two cell lines. Data are mean \pm S.D.

increased with agonist stimulation (Fig. 3, B and C). As shown in Fig. 3C, Bcl-2 levels tended to increase after 4-hour treatment and were significantly upregulated at both 6 and 18 hours compared with time 0 hour. The agonist-induced changes in Bcl-2 were absent in nontransfected HEK293 cells (Fig. 3C). Expression of the proapoptotic protein Bax was not significantly affected by RO5166017 in the presence or absence of mTAAR1 (Fig. 3D). These findings are consistent with our in vivo data from Taar1 KO mice administered MA (Fig. 1). The Bax/Bcl-2 ratio was lower in cells expressing TAAR1 than in nontransfected cells (Fig. 3E).

In Vivo and In Vitro Stimulation of TAAR1 Activates the ERK1/2 Signaling Pathway. The aforementioned evidence suggests that TAAR1 regulates specific intermediates in the apoptotic pathway. To further characterize the MAinduced changes in that signal cascade, we examined the ERK signaling pathway, which plays a role in apoptosis in both cell culture and animal models (Lee et al., 2003; Purcell et al., 2007; Ji et al., 2016). The activation of ERK1/2 was measured in both midbrain tissue from Taar $1 \mathrm{WT}$ and KO mice and in cells stably expressing mTAAR1. We observed higher basal pERK1/2 levels in the midbrain of Taar1 KO mice compared with their WT littermates (Fig. 4). pERK1/2 was dose dependently increased in the midbrain of Taar1 WT mice, while it was dose dependently decreased in Taar $1 \mathrm{KO}$ mice after MA administration (Fig. 4A). At the $4 \times 10 \mathrm{mg} / \mathrm{kg}$ MA level, pERK1/2 activation was increased in Taar1 WT mice compared with saline control mice and KO mice. Total ERK1/2 was unchanged following MA administration and did not differ across genotypes (Fig. 4B).

To determine if activation of TAAR 1 by the selective agonist RO5166017 induces the phosphorylation of ERK1/2, HEK293 and HEK-mTAAR1 cells were treated with $100 \mathrm{nM}$ RO5166017. Dose-response curves indicated that $100 \mathrm{nM}$ RO5166017 (and activation of ERK) was not lethal to cells (data not shown). Both $\mathrm{pERK} 1 / 2$ and total ERK expression levels were measured by western blotting at $0,2,4,6$, and 18 hours after RO5166017 treatment (Fig. 5A). As shown in Fig. 5, A and B, pERK1/2 expression was significantly increased after 4 hours of agonist treatment and expression decreased at RO5166017 exposure 
A

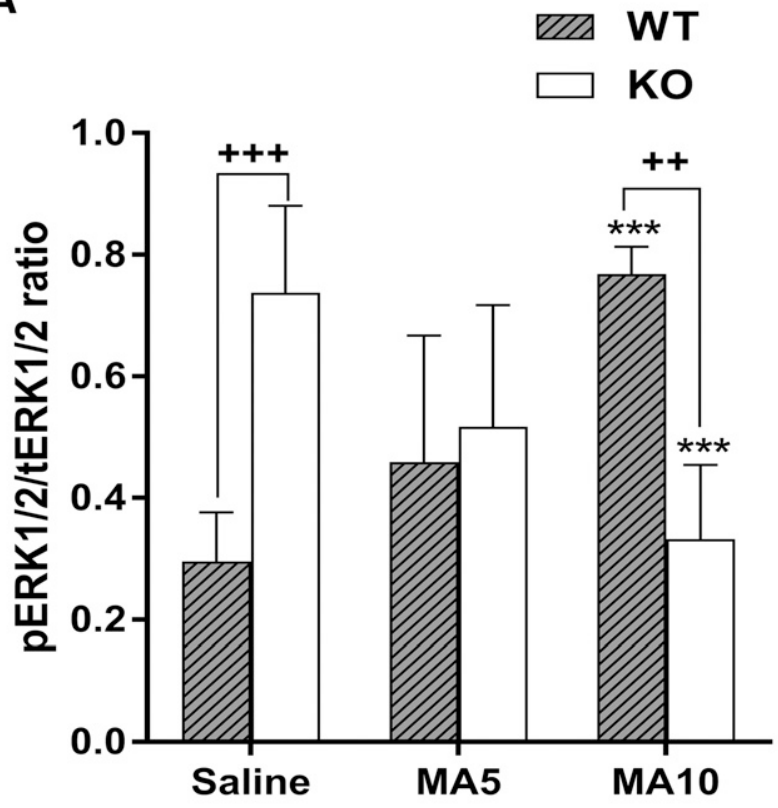

B

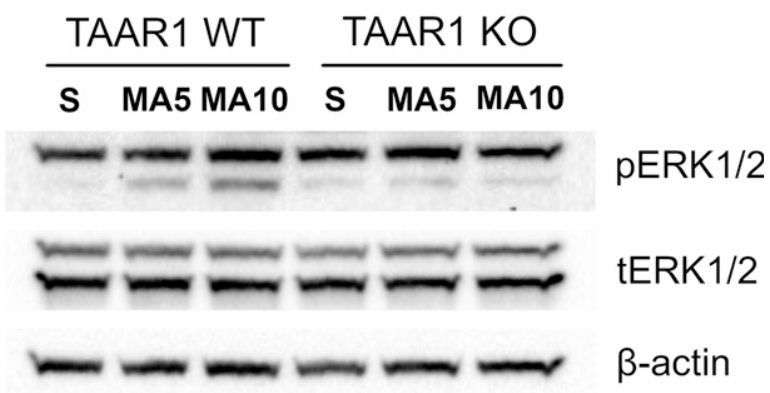

Fig. 4. MA upregulated ERK activation in the midbrain of Taar1 WT mice at 24 hours postinjection, but reduced ERK activation in Taar1 KO mice. (A) Basal (saline-injected) pERK expression was significantly higher in Taar1 KO compared with Taar1 WT mice, and MA dose dependently increased ERK activation in Taar 1 WT mice and decreased ERK activation in Taar1 KO mice compared with saline-injected animals. The levels of pERK1/2 were reduced in Taar1 KO mice at the $4 \times 10 \mathrm{mg} / \mathrm{kg}$ dose of MA compared with WT mice. $* * P<0.01 ; * * * P<0.001$ vs. saline, $++P<0.01$ $+++P<0.001$ between genotypes. For pERK/total ERK (tERK), there was an interaction between genotype $\times$ treatment $[F(4,34)=16.44, P<$ 0.0001 by two-way ANOVA. $N=6$ to 7/genotype/treatment. (B) Representative gels of protein levels. Data are mean \pm S.D.

times longer than 6 hours in mTAAR1-expressing cells. Nontransfected cells were not affected by exposure to drug. We also examined the AKT pathway after RO5166017 treatment. AKT activation involves the phosphorylation of two residues: Thr308 and Ser473 (Alessi et al., 1997). RO5166017 stimulated AKT phosphorylation at Thr308, but not phosphorylation of Ser473 and total AKT (Fig. 5, D and E). To confirm that RO5166017-induced ERK phosphorylation is specific to TAAR1 activation, and is not due to nonspecific effects of the drug, we tested the TAAR1 antagonist EPPTB against RO5166017 activation of ERK phosphorylation. HEK293 or HEK-mTAAR1 cells were incubated with serum-free medium for 3 hours to prevent serum activation of ERK. Cells were preincubated with $10 \mu \mathrm{M}$ EPPTB for 45 minutes before 30-minute treatment of RO5166017. RO5166017-induced ERK phosphorylation was abolished by the antagonist EPPTB, suggesting ERK activation is a specific downstream component of TAAR1 signaling (Fig. 5F). Phosphorylation of AKT at Ser473 was not affected by the agonist or antagonist (Fig. 5F).

TAAR1-Stimulates Bel-2 via Activation of the ERK1/2 Pathway In Vitro. To investigate whether TAAR1 induces Bcl-2 through ERK1/2 activation, we blocked ERK activation with U0126, a mitogen-activated protein kinase/ERK1/2 inhibitor. Cells were pretreated with $10 \mu \mathrm{M}$ U0126 for an hour to prevent ERK activation (pERK1/2 expression), before treatment with RO5166017. Bcl-2 levels were measured at 18 hours, which is the RO5166017-induced peak time for Bcl-2 expression (Fig. 3C). Again, RO5166017 induced ERK1/2 phosphorylation and also increased Bcl-2 expression in mTAAR1-expressing cells (Fig. 6A). Pretreatment with U0126 not only blocked ERK1/2 activation, it also prevented RO5166017-induced Bcl-2 expression (Fig. 6, B and C). Nontransfected cells did not respond to RO5166017 or U0126.

TAAR1 Antagonist Blocks Agonist-Induced pERK1/2 and Bcl-2 Expression In Vitro. To confirm pharmacologically that TAAR1 regulates ERK-mediated Bcl-2 expression, HEK-mTAAR1 and nontransfected cells were preincubated with the TAAR1 antagonist EPPTB $(10 \mu \mathrm{M})$ for 2 hours before 100 nM RO5166017 treatment (18 hours). Both RO5166017induced Bcl-2 (Fig. 7, A and B) and pERK1/2 (Fig. 7, A and C) expression were blocked by the TAAR1 antagonist. Again, cells that did not express mTAAR 1 were not affected by drug treatment.

Blocking AKT Phosphorylation Did Not Prevent TAAR1 Agonist-Induced Bcl-2 Levels. Figure 5, D and E indicate that RO5166017 stimulated the phosphorylation of AKT at Thr308 in addition to stimulating ERK1/2 phosphorylation. To determine if the phosphorylation of AKT Thr308 also contributed to the TAAR1-induced increases in Bcl-2 levels, we blocked the activation of AKT Thr308 with GSK2334470, a selective 3-phosphoinositide-dependent protein kinase inhibitor (Najafov et al., 2011). GSK2334470 selectively blocked AKT phosphorylation at Thr308, but not Ser473 (Fig. 8, A-C). Blocking AKT Thr308 phosphorylation did not affect TAAR1 agonist-induced Bcl-2 changes (Fig. 8E). Interestingly, inhibition of AKT phosphorylation by GSK2334470 increased ERK1/2 activation in the presence of the TAAR 1 agonist in both cell lines (Fig. 8D), indicating there is crosstalk between AKT and ERK pathways. Increased ERK activation appears to be a compensatory effect by blocking AKT phosphorylation. However, the effect was also present in HEK293 WT cells (no TAAR1 expression) (Fig. 8D); this suggests a nonspecific effect of GSK2334470. The increased ERK phosphorylation in the presence of GSK2334470 and RO5166017 did not result in further increases in Bcl-2 levels in TAAR1-expressing cells (Fig. 8E); again, suggesting that blockade of AKT phosphorylation is not part of the TAAR1 signaling cascade that regulates Bcl-2.

\section{Discussion}

We provide evidence for a mechanism through which TAAR1 plays a protective role against MA-induced cell death by upregulating the antiapoptotic protein Bcl-2 through an ERK-dependent, but not AKT-dependent, mechanism. MA causes brain damage in various animal species including humans (Eisch and Marshall, 1998; Deng et al., 2001; Thompson et al., 2004; Yu et al., 2004). Neurochemical events including excitotoxicity, endoplasmic reticulum stress, and dysfunction of the ubiquitin-proteasome system contribute to MA-induced 
A

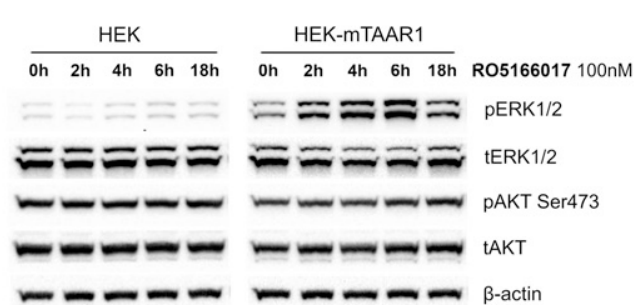

D

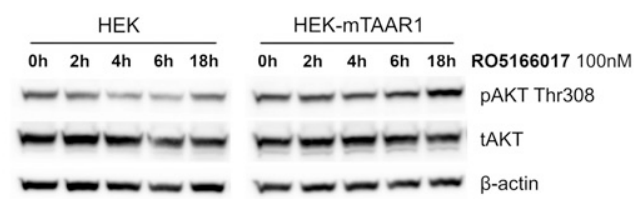

B

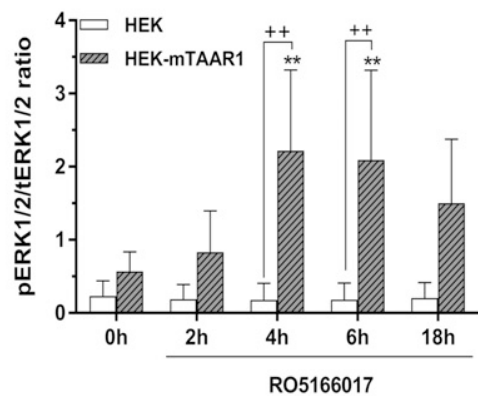

E

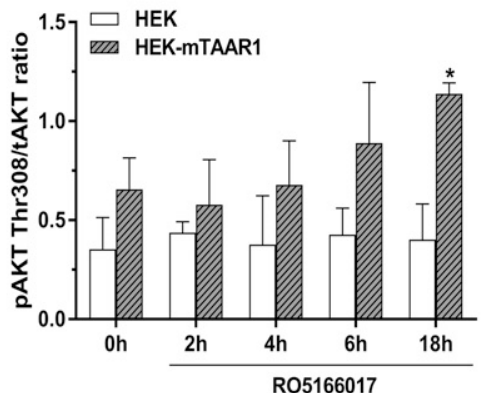

C

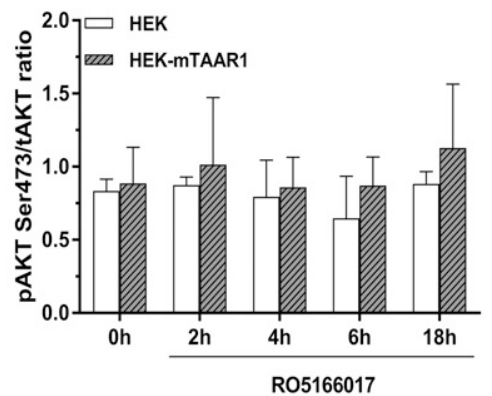

$\mathbf{F}$

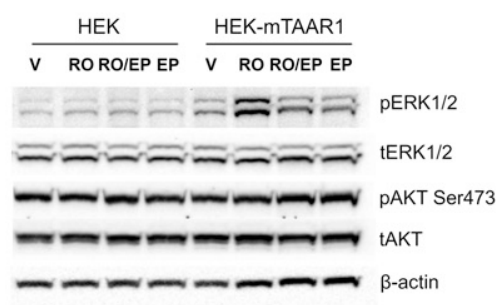

Fig. 5. Activation of TAAR1 stimulated the phosphorylation of ERK1/2. (A) Nontransfected HEK293 or HEK-mTAAR1 cells were stimulated with $100 \mathrm{nM}$ RO5166017, and pERK1/2 and phosphorylated AKT (pAKT) levels were measured at 0, 2, 4, 6 and 18 hours by western blot. (A) Representative gels of protein levels. (B) pERK1/2 levels were higher at 4 and 6 hours in cells expressing mTAAR1. For pERK/total ERK (tERK), there was an interaction between time $\times$ cell line $[F(4,19)=4.508, P<0.01]$. (C) The agonist had no effect on AKT phosphorylation at ser473, but stimulated the phosphorylation at Thr308 (D and E). One-way ANOVA indicated an increase in the activation of AKT Thr308 in HEK-mTAAR1 cells at 18 hours compared with 0 hour $\left({ }^{*} P<0.05\right)$. Nontransfected HEK293 cells lacked agonist-induced ERK1/2 or AKT activation. (F) Nontransfected HEK293 or HEK-mTAAR1 cells were serum starved for 3 hours and then pretreated with $10 \mu \mathrm{M}$ EPPTB for 45 minutes before 30-minute incubation with $100 \mathrm{nM}$ RO5166017. Data shown in $(\mathrm{B}, \mathrm{C}$, and E) represent the average of at least three independent experiments, with each time point conducted in duplicate. Data are mean \pm S.D. $* P<$ 0.05 ; ${ }^{*} P<0.01$ vs. vehicle control or 0 hour, $+P<0.05$; $++P<0.01$ between two cell lines.

neurotoxicity (Mark et al., 2004; Smith et al., 2012; Halpin et al., 2014; Shah and Kumar, 2016; Qie et al., 2017). Furthermore, a number of studies have indicated a role for TAAR1 signaling in MA-induced, glutamatergically mediated neurotoxicity in vitro and in vivo. In primary human astrocytes, activation of TAAR1 by MA decreases glutamate clearance via downregulation of excitatory amino acid transporter 2 expression (Cisneros and Ghorpade, 2014).
A

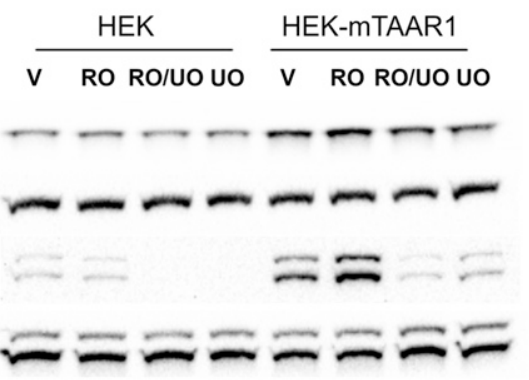

$\mathrm{Bcl}-2$

$\beta$-actin

pERK $1 / 2$

tERK1/2

B

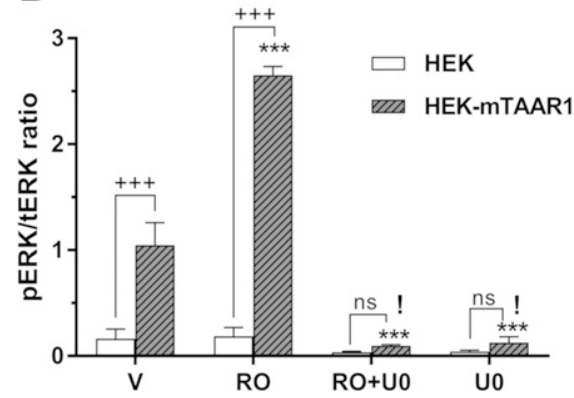

C

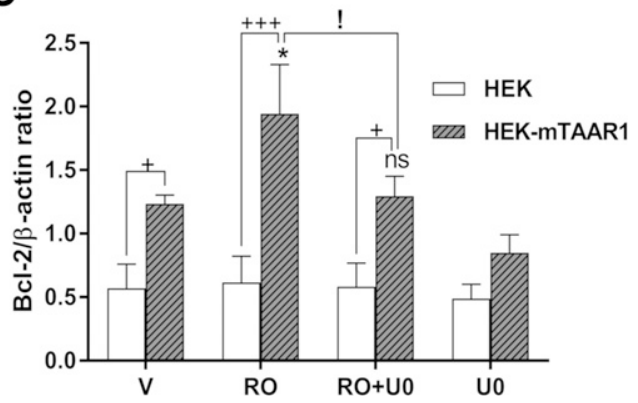

Fig. 6. TAAR1 stimulated Bcl2 levels through the ERK1/2 pathway. Nontransfected HEK293 or HEK-mTAAR1 cells were pretreated with $10 \mu \mathrm{M}$ of U0126 for 1 hour before RO5166017 treatment. TAAR1 agonist-stimulated ERK activation and Bcl-2 expression were measured at 18 hours. (A) Representative gels of protein levels. (B) Pretreatment with U0126 blocked RO5166017-induced pERK1/2 levels in both cell lines. For pERK/total ERK (tERK), two-way ANOVA indicated that there was an interaction between treatment $\times$ cell line $[F(3,16)=214.1$, $P<0.0001]$. (C) Blocking ERK activation with U0126 prevented RO5166017-induced changes in Bcl-2 levels. For Bcl-2, there was an interaction between treatment $\times$ cell line $[F(3,16)=6.058, P<0.01]$ by two-way ANOVA. $* P<0.05$, vs. vehicle control, $+P<0.05,+++P<0.001$ between cell lines: $! P<0.05$ agonist vs. agonist $+\mathrm{U} 0126$. Data shown in (B and C) represent the average of at least three independent experiments, with each time point conducted in duplicate. Data are mean \pm S.D. 


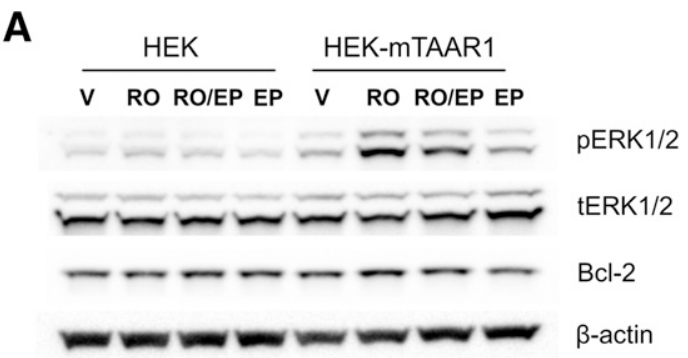

B

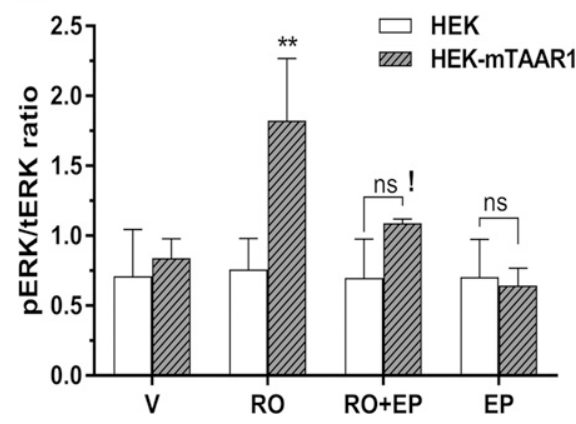

C

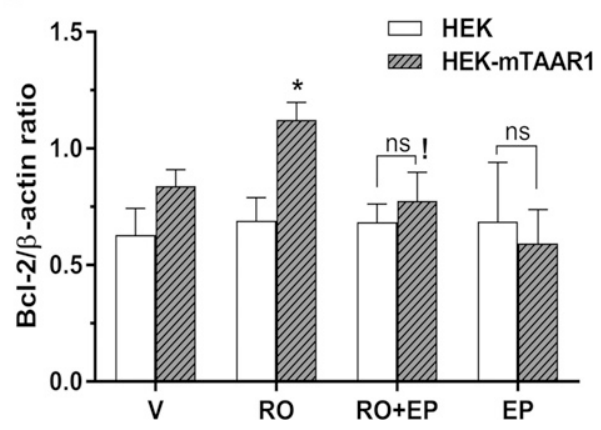

Fig. 7. TAAR1-stimulated Bcl-2 levels were blocked by EPPTB (EP). (A) Nontransfected or HEK-mTAAR1 cells were pretreated with $10 \mu \mathrm{M}$ EPPTB for 2 hours, and then stimulated with 100 nM RO5166017 (RO). Representative gels of protein levels are shown. (B) No ERK activation or Bcl-2 changes were observed in nontransfected cells. However, RO5166017-induced ERK activation or increased Bcl-2 levels were abolished by EPPTB pretreatment. (C) For Bcl-2, there was an interaction between treatment $\times$ cell line $[F(3,16)=4.183, P<0.05]$ by two-way ANOVA. Post hoc test following one-way ANOVA indicated significantly increased Bcl-2 following RO5166017 treatment compared with vehicle control, $\mathrm{RO} / \mathrm{EP}$, and EPPTB alone by one-way ANOVA. No significant difference between RO/EP or EPPTB alone compared with vehicle control. ${ }^{*} P<0.05$; $* * P<0.01$ vs. vehicle control, $! P<0.05$ agonist vs. agonist + EPPTB. Data shown represent the average of three independent experiments, each time point conducted in duplicate. Data are mean \pm S.D.; tERK, total ERK.
Additionally, the TAAR1 agonist RO5166017 prevents 6hydroxydopamine-induced striatal glutamate release (Alvarsson et al., 2015). Activation of TAAR1 induces hypothermia in response to MA and decreases MA-induced neurotoxicity (Miner et al., 2017). However, there are few studies describing the signaling cascade and role of TAAR1 in MA-induced cell death.

The TAAR1 agonists 3-iodothyronamine and tyramine induce apoptosis in malignant B cells endogenously expressing TAAR1. Nonmalignant (normal) B cells also express TAAR1, but they are less sensitive to TAAR1 agonistinduced apoptosis (Wasik et al., 2012). 3-Iodothyronamine protects neurons against apoptosis in a rat model of spinal cord injury and 3-iodothyronamine treatment significantly reduces apoptosis measured using a terminal deoxynucleotidyl transferase dUTP nick end labeling assay. Importantly, the 3-iodothyronamine-reduced apoptosis rate is diminished in animals treated with the TAAR1 antagonist EPPTB (Lv et al., 2018). Taken together, these results suggest that TAAR1 plays a role in the regulation of apoptosis.

Here, we demonstrate that in Taar $1 \mathrm{KO}$ mice the expression of midbrain Bcl-2 is reduced via a non-TAAR1-mediated mechanism after administration of the TAAR1 agonist MA at both 5 and $10 \mathrm{mg} / \mathrm{kg}$, while MA dose dependently increased Bcl-2 in Taar1 WT mice (Fig. 1). This suggests that TAAR1 activation is involved in regulating Bcl-2 levels in response to MA stimulation. However, MA decreases Bcl-2 expression in striatum and neocortex, two dopaminergic terminal areas (Jayanthi et al., 2001; Beauvais et al., 2011) that differ from the (presynaptic) cell body-containing midbrain region. Additionally, there is no obvious DA neuron cell (body) death in the midbrain region after MA administration (Melega et al., 1997; Harvey et al., 2000). Use of a MA preconditioning model indicates that low-dose MA is protective against MA-induced neurotoxicity via the suppression of apoptotic pathways (Takeichi et al., 2012). Bcl-2 expression in the midbrain of the preconditioning model is increased after MA treatment, consistent with our findings. The midbrain, including the substantia nigra and ventral tegmental area, includes multiple nuclei that express TAAR1 (Lindemann et al., 2008). TAAR1-mediated Bcl-2 upregulation in response to MA stimulation could be one of the mechanisms suppressing neuronal apoptosis. Consistent with our in vivo Bcl-2 data (Fig. 1), the selective TAAR1 agonist RO5166017 stimulated Bcl-2 expression in HEK-mTAAR1 cells (Fig. 3), providing direct evidence that TAAR1 regulates the apoptotic pathway. We also found that basal Bcl-2 expression is higher in the midbrain of Taar1 KO mice compared with WT mice. Taar1 KO mice have enhanced amphetamine-induced locomotor activity and increased extracellular DA, norepinephrine, and serotonin levels in the striatum (Wolinsky et al., 2007; Lindemann et al., 2008). Taar1 KO mice also have an increased density of striatal DA D2 receptors (Espinoza et al., 2015). The basal physiologic differences between Taar 1 WT and KO mice could play a role in the difference in basal Bcl-2 levels.

When MA decreased Bcl-2 expression in Taar1 KO mice (Fig. 1), we observed an increase in the ratio of Cl-Casp3/ pro-Casp3 in the same Taar1 KO mice (Fig. 2). Caspase 3 is a major executioner caspase associated with initiation of the downstream death cascade (Wolf et al., 1999). Caspase 3 , a proenzyme, is cleaved and activated by other initiator caspases during apoptosis (Porter and Jänicke, 1999; Wolf et al., 1999). Using an antibody specific to the P17 subunit of caspase 3 , we did not detect changes in cleaved caspase 3 in midbrain samples of Taar 1 mice following MA administration. However, the expression of procaspase was significantly decreased at $10 \mathrm{mg} / \mathrm{kg}$ MA treatment in Taar1 KO mice compared with Taar1 WT mice and saline controls (Fig. 2). The decreased expression resulted in an increased ratio of cleaved caspase3/ procaspase, indicating that more caspase 3 is activated in Taar $1 \mathrm{KO}$ mice after 24 hours with $10 \mathrm{mg} / \mathrm{kg}$ MA treatment. Even though caspase 3 activity is a hallmark of apoptosis, the Bax/Bcl-2 ratio is an important upstream checkpoint associated with vulnerability to apoptosis. In our study, we detected an increased Bax/Bcl-2 ratio in Taar $1 \mathrm{KO}$ mice at 24 hours, suggesting that cells were vulnerable to apoptosis. 
A

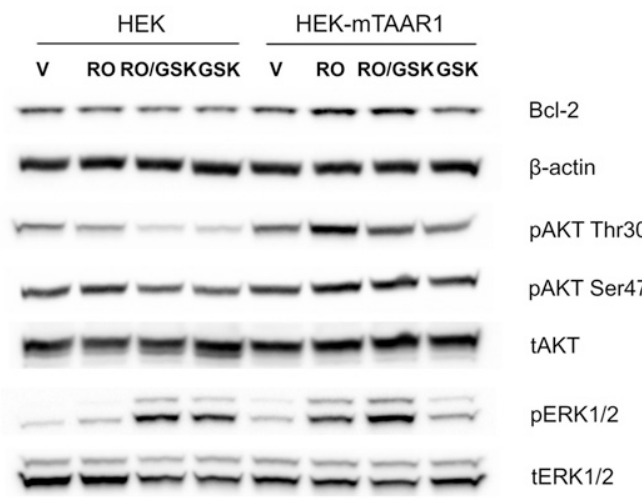

B

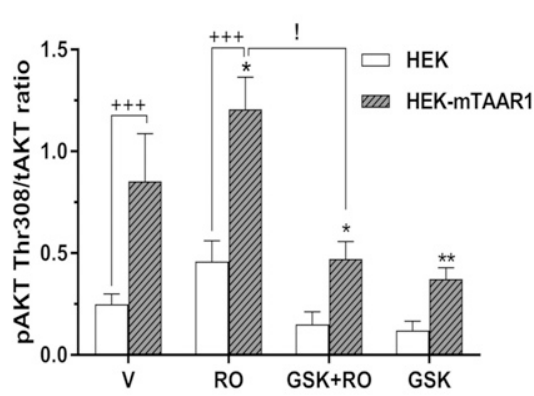

C $\square$ НЕК

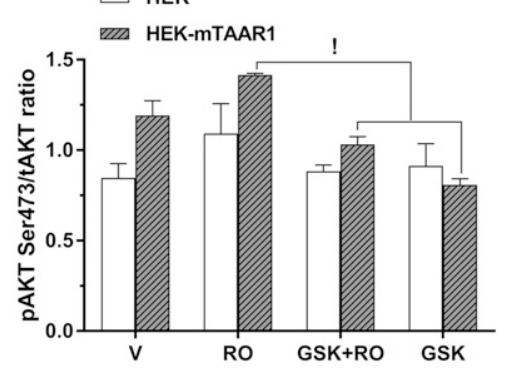

D

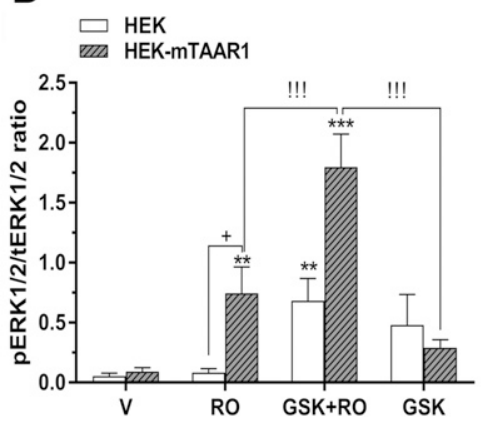

E

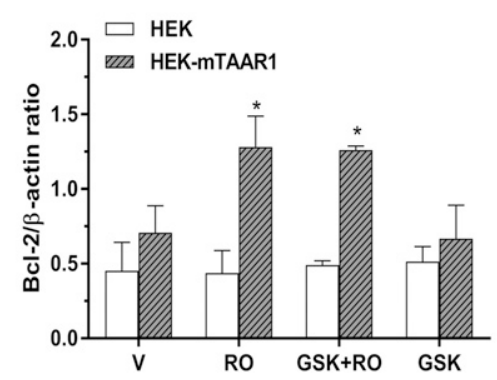

Fig. 8. Inhibition of AKT phosphorylation did not block TAAR1-induced Bcl-2 levels. Nontransfected or HEKmTAAR1 cells were pretreated with $1 \mu \mathrm{M}$ GSK2334470 (GSK) for 90 minutes, and then stimulated with $100 \mathrm{nM}$ RO5166017 (RO) for 18 hours. ERK, AKT, Bcl-2, and internal control ( $\beta$-actin) levels were measured by western blot. (A) Representative gels of protein levels. (B and C) GSK2334470 blocked the AKT phosphorylation at Thr308, but not at Ser473. For phosphorylated AKT (pAKT) Thr308/total AKT (tAKT), there was an interaction between treatment $\times$ cell line $[F(3,16)=6.103, P<$ 0.01 ] by two-way ANOVA. However, blocking AKT phosphorylation resulted in further increases in ERK1/2 levels in both cell lines (D). For pERK/total ERK (tERK), two-way ANOVA indicated an interaction between treatment $\times$ cell line $[F(3,16)=18.5, P<0.0001]$. Inhibiting of AKT phosphorylation did not block RO5166017-induced Bcl-2 levels (E). For Bcl-2, there was an interaction between treatment $\times$ cell line $[F(3,16)=7.633, P<$ $0.01]$ by two-way ANOVA. Post hoc test following twoway ANOVA indicated increased Bcl-2 following RO5166017 or GSK + RO treatment compared with vehicle control, but not GSK alone. $* P<0.05$; $* * P<0.01$; $* * * P<0.001$ vs. vehicle control, $+P<0.05 ;+++P<$ 0.001 between two cell lines. $! P<0.05$ agonist vs. agonist + GSK or GSK alone. Data shown represent the average of three independent experiments, each time point conducted in duplicate. Data are mean \pm S.D.
This change might precede apoptotic events (Deng and Cadet, 2000). Further studies should investigate caspase 3 activation and expression at later treatment time points, such as at 3 and 5 days, following MA administration; only when HEK cells were stimulated with staurosporine, an inducer of apoptosis, could we detect the cleaved caspase 3 (data not shown). The lack of detection of cleaved caspase 3 in cells could also be due to its rapid degradation (Tawa et al., 2004). Pro-Casp3 levels were detectable in cells, but were not affected by either TAAR1 agonist or antagonist in the cells (data not shown).

TAAR1 signaling involves the activation of protein kinase A and protein kinase C (Xie and Miller, 2007; Panas et al., 2012), and recent reports suggest that the mitogen-activated protein kinase cascade is involved in TAAR1 signaling (Espinoza et al., 2018; Michael et al., 2019). Additionally, amphetamine (AMPH) regulates DA and glutamate transporter trafficking by activation of the small GTPase RhoA and cAMP signaling (Wheeler et al., 2015). TAAR1 is an intracellular target of AMPH and mediates AMPH-induced RhoA activation and cAMP signaling in discrete subcellular domains by coupling with different $\mathrm{G}$ protein isoforms (Underhill et al., 2019) This indicates that activation of different signaling pathways by TAAR1 in different subcellular locations is involved in diverse cellular events. In support of this hypothesis, a very recent report has indicated that MA-induced toxicity is mediated by TAAR 1 via regulation of vesicular monoamine transporter 2 (but not the dopamine transporter) function in specific cellular fractions (Miner et al., 2019). In our study, activation of TAAR1 led to increased cAMP and upregulated Bcl-2 levels, suggesting that this pathway has a specific protective role against AMPH- or MA-induced neurotoxicity.

ERK signaling plays an important role in cell survival, and ERK activation in response to different stimuli inhibits apoptosis by regulating the expression of different apoptotic proteins (Lee et al., 2003; Purcell et al., 2007; Subramanian and Shaha, 2007). The results of this study demonstrate that both MA and the TAAR1 agonist RO5166017 induce ERK1/2 phosphorylation in vivo and in vitro, respectively. Importantly, inhibiting ERK phosphorylation blocked Bcl-2 expression, suggesting that ERK1/2 activation is required for TAAR1-stimulated Bcl-2 expression. RO5166017 also stimulated AKT phosphorylation at Thr308 (Fig. 8). However, blocking phosphorylated 


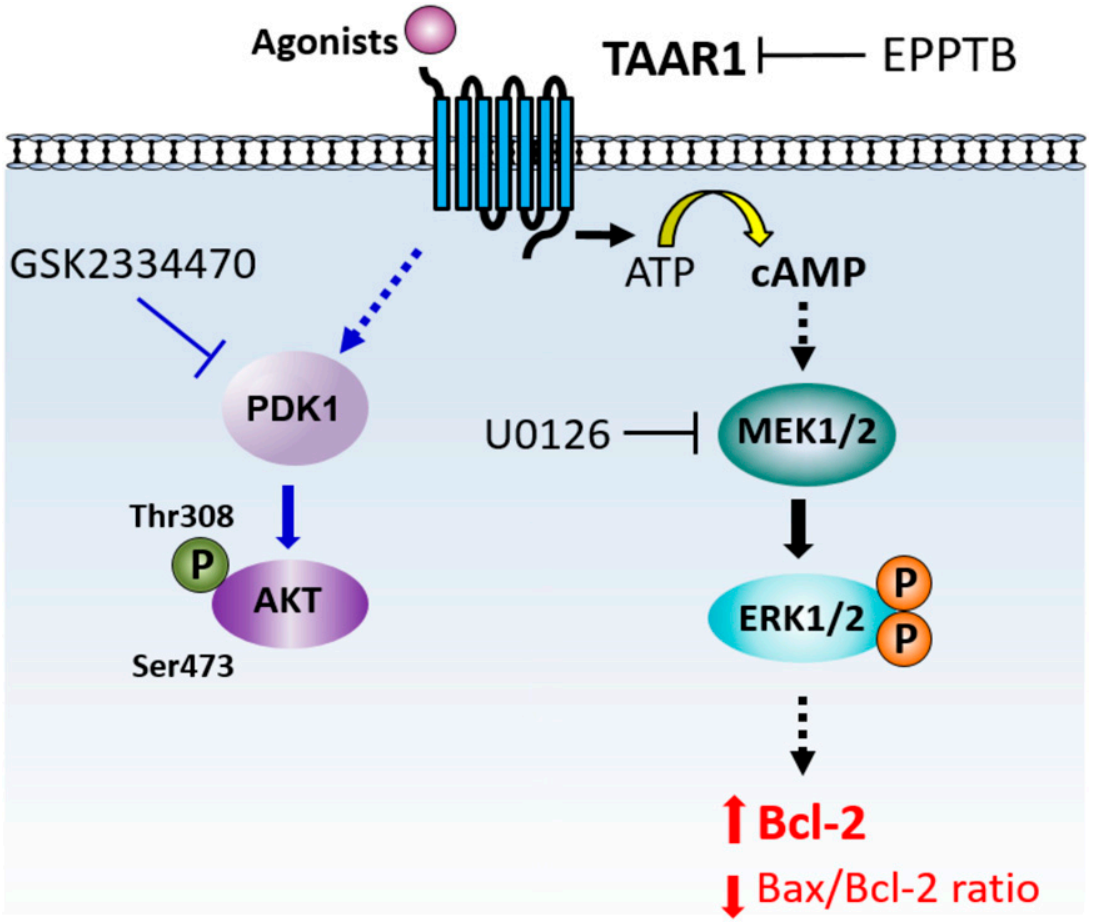

Fig. 9. TAAR1 signaling pathway/apoptotic pathway components. Activation of TAAR1 elicits cAMP accumulation and results in activation of ERK1/2. TAAR1 downstream signaling components increase antiapoptotic protein Bcl-2, but do not change the proapoptotic protein, Bax. This leads to a decreased Bax/Bcl-2 ratio, which could be protective, preventing apoptosis. The TAAR 1 antagonist EPPTB blocks both ERK1/2 phosphorylation and changes in Bcl-2 levels. The TAAR1 agonist increased AKT phosphorylation at Thr308, but not at Ser473, which is not involved in TAAR1-induced apoptotic signaling.

AKT Thr308 by GSK2334470 did not prevent TAAR1 agonistinduced Bcl-2 increase. Instead, blocking AKT was associated with increased ERK phosphorylation in WT and transfected cells, suggested AKT is not specific to TAAR1 apoptotic signaling. ERK1 and ERK2 are 84\% identical in their protein sequence, which results in functional redundancy (Buscà et al., 2016). In our study, the expression levels of ERK1 and ERK2 were different in the animal tissues and cultured cells: ERK1 was dominant in mouse midbrain tissue and ERK2 was dominant in the cultured cells. A specific role for ERK2 in response to the DA metabolite 3-methoxytyramine in TAAR1 WT mice compared with $\mathrm{KO}$ mice has been reported (Sotnikova et al., 2010). Even though there are different expression levels of ERK1 and ERK2 in our models, the changes in ERK1 and ERK2 phosphorylation in response to agonist stimulation were similar, suggesting both isoforms are involved.

Previous reports have indicated that the ERK signaling cascade is involved in multiple drug reward and addiction models and regulates neuronal plasticity (Lu et al., 2005; Berglind et al., 2007; Edwards et al., 2009, 2012; Wang et al., 2012; Gomez et al., 2015). Thus, ERK1/2 could be an important modulator in chronic addiction and disease. We now demonstrate that a specific receptor and signaling pathway leading to ERK1/2 activation is a possible pharmacological target for treatment development.

In summary, activation of TAAR1 leads to increased Bcl-2 expression in vivo and in vitro. This change is mediated by an ERK1/2-dependent pathway (Fig. 9) and our data provide more evidence for TAAR 1 as a therapeutic target for drug addiction and neurodegenerative diseases.

\section{Acknowledgments}

We thank the Oregon Health and Science University Medicinal Chemistry Core for synthesizing RO5166017 and David K. Grandy for providing the Taar1 $\mathrm{KO}$ and WT mice.

\section{Authorship Contributions}

Participated in research design: Shi, Eshleman, Janowsky.

Conducted experiments: Shi, Swanson, Miner.

Performed data analysis: Shi, Eshleman, Janowsky.

Wrote or contributed to the writing of the manuscript: Shi, Swanson, Miner, Eshleman, Janowsky.

\section{References}

Alessi DR, James SR, Downes CP, Holmes AB, Gaffney PR, Reese CB and Cohen P (1997) Characterization of a 3-phosphoinositide-dependent protein kinase which phosphorylates and activates protein kinase $\mathrm{B} \alpha$. Curr Biol 7:261-269.

Alvarsson A, Zhang X, Stan TL, Schintu N, Kadkhodaei B, Millan MJ, Perlmann T, and Svenningsson P (2015) Modulation by trace amine-associated receptor 1 of experimental Parkinsonism, L-DOPA responsivity, and glutamatergic neurotransmission. J Neurosci 35:14057-14069.

Asif-Malik A, Hoener MC, and Canales JJ (2017) Interaction between the trace amine-associated receptor 1 and the dopamine $D_{2}$ receptor controls cocaine's neurochemical actions. Sci Rep 7:13901.

Beauvais G, Atwell K, Jayanthi S, Ladenheim B, and Cadet JL (2011) Involvement of dopamine receptors in binge methamphetamine-induced activation of endoplasmic reticulum and mitochondrial stress pathways. PLoS One 6:e28946.

Berglind WJ, See RE, Fuchs RA, Ghee SM, Whitfield TW Jr, Miller SW, and McGinty JF (2007) A BDNF infusion into the medial prefrontal cortex suppresses cocaine seeking in rats. Eur $J$ Neurosci 26:757-766.

Borowsky B, Adham N, Jones KA, Raddatz R, Artymyshyn R, Ogozalek KL, Durkin MM, Lakhlani PP, Bonini JA, Pathirana S, et al. (2001) Trace amines: identification of a family of mammalian G protein-coupled receptors. Proc Natl Acad Sci USA 98:8966-8971.

Bradaia A, Trube G, Stalder H, Norcross RD, Ozmen L, Wettstein JG, Pinard A, Buchy D, Gassmann M, Hoener MC, et al. (2009) The selective antagonist EPPTB reveals TAAR1-mediated regulatory mechanisms in dopaminergic neurons of the mesolimbic system. Proc Natl Acad Sci USA 106:20081-20086.

Bunzow JR, Sonders MS, Arttamangkul S, Harrison LM, Zhang G, Quigley DI, Darland T, Suchland KL, Pasumamula S, Kennedy JL, et al. (2001) Amphetamine, 3,4-methylenedioxymethamphetamine, lysergic acid diethylamide, and metabolites of the catecholamine neurotransmitters are agonists of a rat trace amine receptor. Mol Pharmacol 60:1181-1188.

Buscà R, Pouysségur J, and Lenormand P (2016) ERK1 and ERK2 map kinases: specific roles or functional redundancy? Front Cell Dev Biol 4:53.

Cadet JL and Brannock C (1998) Free radicals and the pathobiology of brain dopamine systems. Neurochem Int 32:117-131.

Cadet JL, Ordonez SV, and Ordonez JV (1997) Methamphetamine induces apoptosis in immortalized neural cells: protection by the proto-oncogene, bcl-2. Synapse $\mathbf{2 5}$ : 176-184.

Choi HJ, Yoo TM, Chung SY, Yang JS, Kim JI, Ha ES, and Hwang O (2002) Methamphetamine-induced apoptosis in a CNS-derived catecholaminergic cell line. Mol Cells 13:221-227. 
Cisneros IE and Ghorpade A (2014) Methamphetamine and HIV-1-induced neurotoxicity: role of trace amine associated receptor 1 cAMP signaling in astrocytes. Neuropharmacology 85:499-507.

Deng X and Cadet JL (2000) Methamphetamine-induced apoptosis is attenuated in the striata of copper-zinc superoxide dismutase transgenic mice. Brain Res $\mathrm{Mol}$ Brain Res 83:121-124.

Deng X, Cai NS, McCoy MT, Chen W, Trush MA, and Cadet JL (2002) Methamphetamine induces apoptosis in an immortalized rat striatal cell line by activating the mitochondrial cell death pathway. Neuropharmacology 42:837-845.

Deng X, Wang Y, Chou J, and Cadet JL (2001) Methamphetamine causes widespread apoptosis in the mouse brain: evidence from using an improved TUNEL histochemical method. Brain Res Mol Brain Res 93:64-69.

Edwards S, Graham DL, Whisler KN, and Self DW (2009) Phosphorylation of GluR1, ERK, and CREB during spontaneous withdrawal from chronic heroin selfadministration Synapse 63:224-235.

Edwards S, Vendruscolo LF, Schlosburg JE, Misra KK, Wee S, Park PE, Schulteis G, and Koob GF (2012) Development of mechanical hypersensitivity in rats during heroin and ethanol dependence: alleviation by $\mathrm{CRF}_{1}$ receptor antagonism. Neuropharmacology 62:1142-1151.

Eisch AJ and Marshall JF (1998) Methamphetamine neurotoxicity: dissociation of striatal dopamine terminal damage from parietal cortical cell body injury. Synapse 30:433-445.

Espinoza S, Ghisi V, Emanuele M, Leo D, Sukhanov I, Sotnikova TD, Chieregatti E, and Gainetdinov RR (2015) Postsynaptic D2 dopamine receptor supersensitivity in the striatum of mice lacking TAAR1. Neuropharmacology 93:308-313.

Espinoza S, Leo D, Sotnikova TD, Shahid M, Kääriäinen TM, and Gainetdinov RR (2018) Biochemical and functional characterization of the trace amine-associated receptor 1 (TAAR1) agonist RO5263397. Front Pharmacol 9:645.

Fleckenstein AE, Metzger RR, Wilkins DG, Gibb JW, and Hanson GR (1997) Rapid and reversible effects of methamphetamine on dopamine transporters. J Pharmacol Exp Ther 282:834-838.

Gomez AM, Sun WL, Midde NM, Harrod SB, and Zhu J (2015) Effects of environmental enrichment on ERK1/2 phosphorylation in the rat prefrontal cortex following nicotineinduced sensitization or nicotine self-administration. Eur $J$ Neurosci 41:109-119.

Halpin LE, Northrop NA, and Yamamoto BK (2014) Ammonia mediates methamphetamine-induced increases in glutamate and excitotoxicity. Neuropsychopharmacology 39:1031-1038.

Harkness JH, Shi X, Janowsky A, and Phillips TJ (2015) Trace amine-associated receptor 1 regulation of methamphetamine intake and related traits. Neuropsychopharmacology 40:2175-2184.

Harmeier A, Obermueller S, Meyer CA, Revel FG, Buchy D, Chaboz S, Dernick G, Wettstein JG, Iglesias A, Rolink A, et al. (2015) Trace amine-associated receptor 1 activation silences GSK3 $\beta$ signaling of TAAR1 and D2R heteromers. Eur Neuropsychopharmacology 25:2049-2061.

Hart ME, Suchland KL, Miyakawa M, Bunzow JR, Grandy DK, and Scanlan TS (2006) Trace amine-associated receptor agonists: synthesis and evaluation of thyronamines and related analogues. J Med Chem 49:1101-1112.

Harvey DC, Lacan G, Tanious SP, and Melega WP (2000) Recovery from methamphetamine induced long-term nigrostriatal dopaminergic deficits without substantia nigra cell loss. Brain Res 871:259-270.

Huang W, Xie WB, Qiao D, Qiu P, Huang E, Li B, Chen C, Liu C, Wang Q, Lin Z, et al. (2015) Caspase-11 plays an essential role in methamphetamine-induced dopaminergic neuron apoptosis. Toxicol Sci 145:68-79.

Jayanthi S, Deng X, Bordelon M, McCoy MT, and Cadet JL (2001) Methamphetamine causes differential regulation of pro-death and anti-death Bcl-2 genes in the mouse neocortex FASEB J 15:1745-1752.

Jayanthi S, Deng X, Noailles PA, Ladenheim B, and Cadet JL (2004) Methamphetamine induces neuronal apoptosis via cross-talks between endoplasmic reticulum and mitochondria-dependent death cascades. FASEB $J$ 18:238-251.

Ji Y, Dai Z, Wu G, and Wu Z (2016) 4-Hydroxy-2-nonenal induces apoptosis by activating ERK1/2 signaling and depleting intracellular glutathione in intestinal epithelial cells. Sci Rep 6:32929.

Kadota T and Kadota K (2004) Neurotoxic morphological changes induced in the medial prefrontal cortex of rats behaviorally sensitized to methamphetamine. Arch Histol Cytol 67:241-251.

Korsmeyer SJ, Shutter JR, Veis DJ, Merry DE, and Oltvai ZN (1993) Bcl-2/Bax: a rheostat that regulates an anti-oxidant pathway and cell death. Semin Cancer Biol 4:327-332.

Lee YJ, Cho HN, Soh JW, Jhon GJ, Cho CK, Chung HY, Bae S, Lee SJ, and Lee YS (2003) Oxidative stress-induced apoptosis is mediated by ERK1/2 phosphorylation. Exp Cell Res 291:251-266.

Lindemann L, Meyer CA, Jeanneau K, Bradaia A, Ozmen L, Bluethmann H, Bettler B, Wettstein JG, Borroni E, Moreau JL, et al. (2008) Trace amineassociated receptor 1 modulates dopaminergic activity. J Pharmacol Exp Ther 324:948-956.

Lu L, Hope BT, Dempsey J, Liu SY, Bossert JM, and Shaham Y (2005) Central amygdala ERK signaling pathway is critical to incubation of cocaine craving. Nat Neurosci 8:212-219.

Lv J, Liao J, Tan W, Yang L, Shi X, Zhang H, Chen L, Wang S, and Li Q (2018) 3Iodothyronamine acting through an anti-apoptotic mechanism is neuroprotective against spinal cord injury in rats. Ann Clin Lab Sci 48:736-742.

Mark KA, Soghomonian JJ, and Yamamoto BK (2004) High-dose methamphetamine acutely activates the striatonigral pathway to increase striatal glutamate and mediate long-term dopamine toxicity. $J$ Neurosci 24 $11449-11456$

Mattson MP (2000) Apoptosis in neurodegenerative disorders. Nat Rev Mol Cell Biol 1:120-129.

McConnell SE, O'Banion MK, Cory-Slechta DA, Olschowka JA, and Opanashuk LA (2015) Characterization of binge-dosed methamphetamine-induced neurotoxicity and neuroinflammation. Neurotoxicology 50:131-141.
Melega WP, Raleigh MJ, Stout DB, Lacan G, Huang SC, and Phelps ME (1997) Recovery of striatal dopamine function after acute amphetamine- and methamphetamineinduced neurotoxicity in the vervet monkey. Brain Res 766:113-120.

Michael ES, Covic L, and Kuliopulos A (2019) Trace amine-associated receptor 1 (TAAR1) promotes anti-diabetic signaling in insulin-secreting cells. J Biol Chem 294:4401-4411.

Miller GM, Verrico CD, Jassen A, Konar M, Yang H, Panas H, Bahn M, Johnson R, and Madras BK (2005) Primate trace amine receptor 1 modulation by the dopamine transporter. J Pharmacol Exp Ther 313:983-994.

Miner NB, Elmore JS, Baumann MH, Phillips TJ, and Janowsky A (2017) Trace amine-associated receptor 1 regulation of methamphetamine-induced neurotoxicity. Neurotoxicology 63:57-69.

Miner NB, Phillips TJ, and Janowsky A (2019) The role of biogenic amine transporters in trace amine-associated receptor 1 regulation of methamphetamineinduced neurotoxicity. $J$ Pharmacol Exp Ther DOI: 10.1124/jpet.119.258970 [published ahead of print].

Najafov A, Sommer EM, Axten JM, Deyoung MP, and Alessi DR (2011) Characterization of GSK2334470, a novel and highly specific inhibitor of PDK1. Biochem $J$ 433:357-369.

O'Callaghan JP and Miller DB (1994) Neurotoxicity profiles of substituted amphetamines in the C57BL/6J mouse. J Pharmacol Exp Ther 270:741-751.

Panas MW, Xie Z, Panas HN, Hoener MC, Vallender EJ, and Miller GM (2012) Trace amine associated receptor 1 signaling in activated lymphocytes. J Neuroimmune Pharmacol 7:866-876.

Porter AG and Jänicke RU (1999) Emerging roles of caspase-3 in apoptosis. Cell Death Differ 6:99-104.

Purcell NH, Wilkins BJ, York A, Saba-El-Leil MK, Meloche S, Robbins J, and Molkentin JD (2007) Genetic inhibition of cardiac ERK1/2 promotes stressinduced apoptosis and heart failure but has no effect on hypertrophy in vivo. Proc Natl Acad Sci USA 104:14074-14079.

Qie X, Wen D, Guo H, Xu G, Liu S, Shen Q, Liu Y, Zhang W, Cong B, and Ma C (2017) Endoplasmic reticulum stress mediates methamphetamine-induced blood-brain barrier damage. Front Pharmacol 8:639.

Shah A and Kumar A (2016) Methamphetamine-mediated endoplasmic reticulum (ER) stress induces type-1 programmed cell death in astrocytes via ATF6, IRE1 $\alpha$ and PERK pathways. Oncotarget 7:46100-46119

Shi X, Walter NA, Harkness JH, Neve KA, Williams RW, Lu L, Belknap JK, Eshleman AJ, Phillips TJ, and Janowsky A (2016) Genetic polymorphisms affect mouse and human trace amine-associated receptor 1 function. PLoS One 11: e0152581.

Smith SB, Maixner DW, Fillingim RB, Slade G, Gracely RH, Ambrose K, Zaykin DV, Hyde C, John S, Tan K, et al. (2012) Large candidate gene association study reveals genetic risk factors and therapeutic targets for fibromyalgia. Arthritis Rheum 64: 584-593.

Sotnikova TD, Beaulieu JM, Espinoza S, Masri B, Zhang X, Salahpour A, Barak LS, Caron MG, and Gainetdinov RR (2010) The dopamine metabolite 3-methoxytyramine is a neuromodulator. PLoS One 5:e13452.

Stumm G, Schlegel J, Schäfer T, Würz C, Mennel HD, Krieg JC, and Vedder H (1999) Amphetamines induce apoptosis and regulation of bcl-x splice variants in neocortical neurons. FASEB J 13:1065-1072.

Subramanian M and Shaha C (2007) Up-regulation of Bcl-2 through ERK phosphorylation is associated with human macrophage survival in an estrogen microenvironment. J Immunol 179:2330-2338.

Takeichi T, Wang EL, and Kitamura O (2012) The effects of low-dose methamphetamine pretreatment on endoplasmic reticulum stress and methamphetamine neurotoxicity in the rat midbrain. Leg Med (Tokyo) 14:69-77.

Tawa P, Hell K, Giroux A, Grimm E, Han Y, Nicholson DW, and Xanthoudakis S (2004) Catalytic activity of caspase-3 is required for its degradation: stabilization of the active complex by synthetic inhibitors. Cell Death Differ 11 439-447.

Thomas DM, Walker PD, Benjamins JA, Geddes TJ, and Kuhn DM (2004) Methamphetamine neurotoxicity in dopamine nerve endings of the striatum is associated with microglial activation. J Pharmacol Exp Ther 311:1-7.

Thompson PM, Hayashi KM, Simon SL, Geaga JA, Hong MS, Sui Y, Lee JY, Toga AW, Ling W, and London ED (2004) Structural abnormalities in the brains of human subjects who use methamphetamine. J Neurosci 24 6028-6036.

Tulloch I, Afanador L, Mexhitaj I, Ghazaryan N, Garzagongora AG, and Angulo JA (2011) A single high dose of methamphetamine induces apoptotic and necrotic striatal cell loss lasting up to 3 months in mice. Neuroscience 193: $162-169$.

Underhill SM, Hullihen PD, Chen J, Fenollar-Ferrer C, Rizzo MA, Ingram SL, and Amara SG (2019) Amphetamines signal through intracellular TAAR1 receptors coupled to $\mathrm{G} \alpha_{13}$ and $\mathrm{G} \alpha_{\mathrm{S}}$ in discrete subcellular domains. Mol Psychiatry DOI: 10.1038/s41380-019-0469-2 [published ahead of print]

Wang WS, Kang S, Liu WT, Li M, Liu Y, Yu C, Chen J, Chi ZQ, He L, and Liu JG (2012) Extinction of aversive memories associated with morphine withdrawal requires ERK-mediated epigenetic regulation of brain-derived neurotrophic factor transcription in the rat ventromedial prefrontal cortex. J Neurosci 32 : 13763-13775.

Wasik AM, Millan MJ, Scanlan T, Barnes NM, and Gordon J (2012) Evidence for functional trace amine associated receptor-1 in normal and malignant B cells. Leuk Res 36:245-249.

Watts VJ, Wiens BL, Cumbay MG, Vu MN, Neve RL, and Neve KA (1998) Selective activation of $\mathrm{G} \alpha$, by $\mathrm{D}_{2 \mathrm{~L}}$ dopamine receptors in NS20Y neuroblastoma cells. $J$ Neurosci 18:8692-8699.

Wheeler DS, Underhill SM, Stolz DB, Murdoch GH, Thiels E, Romero G, and Amara SG (2015) Amphetamine activates Rho GTPase signaling to mediate dopamine transporter internalization and acute behavioral effects of amphetamine. Proc Nat Acad Sci USA 112:E7138-E7147. 
Wolf BB, Schuler M, Echeverri F, and Green DR (1999) Caspase-3 is the primary activator of apoptotic DNA fragmentation via DNA fragmentation factor-45/inhibitor of caspase-activated DNase inactivation. $\mathrm{J}$ Biol Chem 274:30651-30656

Wolinsky TD, Swanson CJ, Smith KE, Zhong H, Borowsky B, Seeman P, Branchek T, and Gerald CP (2007) The trace amine 1 receptor knockout mouse: an animal model with relevance to schizophrenia. Genes Brain Behav 6:628-639.

Xie Z and Miller GM (2007) Trace amine-associated receptor 1 is a modulator of the dopamine transporter. J Pharmacol Exp Ther 321:128-136.
Yu J, Wang J, Cadet JL, and Angulo JA (2004) Histological evidence supporting a role for the striatal neurokinin-1 receptor in methamphetamine-induced neurotoxicity in the mouse brain. Brain Res 1007:124-131.

Address correspondence to: Aaron Janowsky, Research Service (RD-22) Veterans Affairs Portland Health Care System, 3710 SW US Veterans Hospital Rd, Portland, OR 97239-3098. E-mail: janowsky@ohsu.edu 